\title{
Improvement of Chronic Back Pain or Failed Back Surgery with Vitamin D Repletion: A Case Series
}

\author{
Gerry Schwalfenberg, $M D$
}

This article reviews 6 selected cases of improvement/resolution of chronic back pain or failed back surgery after vitamin D repletion in a Canadian family practice setting. Pub Med was searched for articles on chronic back pain, failed back surgery, and vitamin D deficiency. Chronic low back pain and failed back surgery may improve with repletion of vitamin D from a state of deficiency/insufficiency to sufficiency. Vitamin D insufficiency is common; repletion of vitamin D to normal levels in patients who have chronic low back pain or have had failed back surgery may improve quality of life or, in some cases, result in complete resolution of symptoms. (J Am Board Fam Med 2009;22:69-74.)

Back pain is the most common neurological complaint in North America, second only to headache. Chronic back pain is often progressive and the cause may be difficult to determine. In America, more than $\$ 50$ billion are spent each year on treatment. ${ }^{1}$ Low back pain (LBP) and proximal myopathy are also common symptoms of vitamin $\mathrm{D}$ deficiency and osteomalacia. ${ }^{2,3}$ There are many risk factors for vitamin D insufficiency or deficiency, including lack of sun exposure, inadequate dietary intake, darker skin color, age, obesity, and the use of various medications. The prevalence of vitamin $\mathrm{D}$ insufficiency/deficiency is high in Canada (where the patients in this report are located), especially during the winter.

The case reports described in Table 1 were from one solo practice. There were 4 patients who had chronic back pain for more than a year and 2 patients who suffered for more than 3 years from failed back surgery. Repletion of inadequate vitamin D levels $(<80 \mathrm{nmol} / \mathrm{L})$ demonstrated significant improvement or complete resolution of

This article was externally peer reviewed.

Submitted 2 February 2008; revised 16 April 2008; accepted 17 April 2008.

From the Department of Family Medicine, University of Alberta, Canada.

Funding: none.

Conflict of interest: none declared.

Corresponding author: Gerry Schwalfenberg, MD, CCFP, Clinical Instructor, Department of Family Medicine, University of Alberta, \#301, 9509-156 St, Edmonton, Alberta, Canada T5P 4J5 (E-mail: gschwalf@telus.net). chronic LBP symptoms in these patients, and has been reported in literature before. ${ }^{3,4}$

\section{Discussion}

PubMed was searched for articles, using the search terms "low back pain," "disk surgery," "musculoskeletal pain," and "vitamin D deficiency." As stated before, LBP is a common condition; it is estimated at approximately $5 \%$ of patients presenting in primary care have LBP, many of which become chronic.

Vitamin D is required for the differentiation, proliferation, and maturation of cartilage cells and for the production of proteoglycan synthesis in articular chondrocytes. Restoring vitamin D levels to normal in patients with osteomalcia has resulted in complete resolution of pain within 4 weeks. ${ }^{5}$ Improvement in back pain and weakness in patients with osteomalcia has also been noted. Patients who have chronic, nonspecific LBP or have had failed back surgery may have an underlying vitamin $\mathrm{D}$ insufficiency/deficiency. ${ }^{6}$

Risk factors for persistence or recurrence of LBP after surgery include infection and smoking. A less common reason is low vitamin D levels. Repletion with $1000 \mathrm{IU} /$ day improves vitamin D status by approximately 20 to $25 \mathrm{nmol} / \mathrm{L}$, and 2000/day IU will improve levels by 40 to 50 , except in darkerskinned people, who may require significantly more. Patients with back pain who also have other risk factors for low vitamin $\mathrm{D}$ levels may benefit from a screening $25(\mathrm{OH}) \mathrm{D}$ level and repletion therapy. Muscle pain has been commonly seen in 


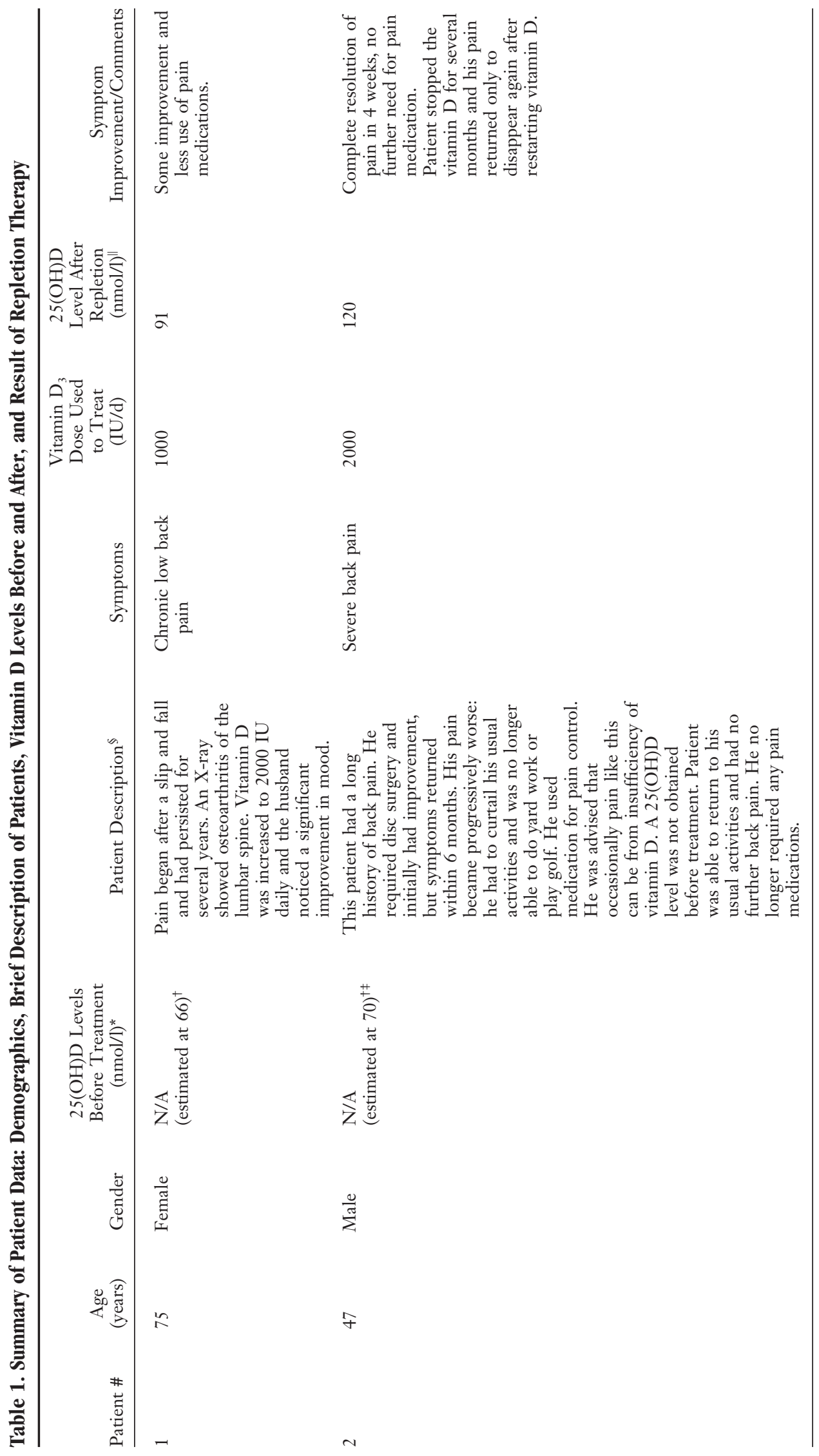




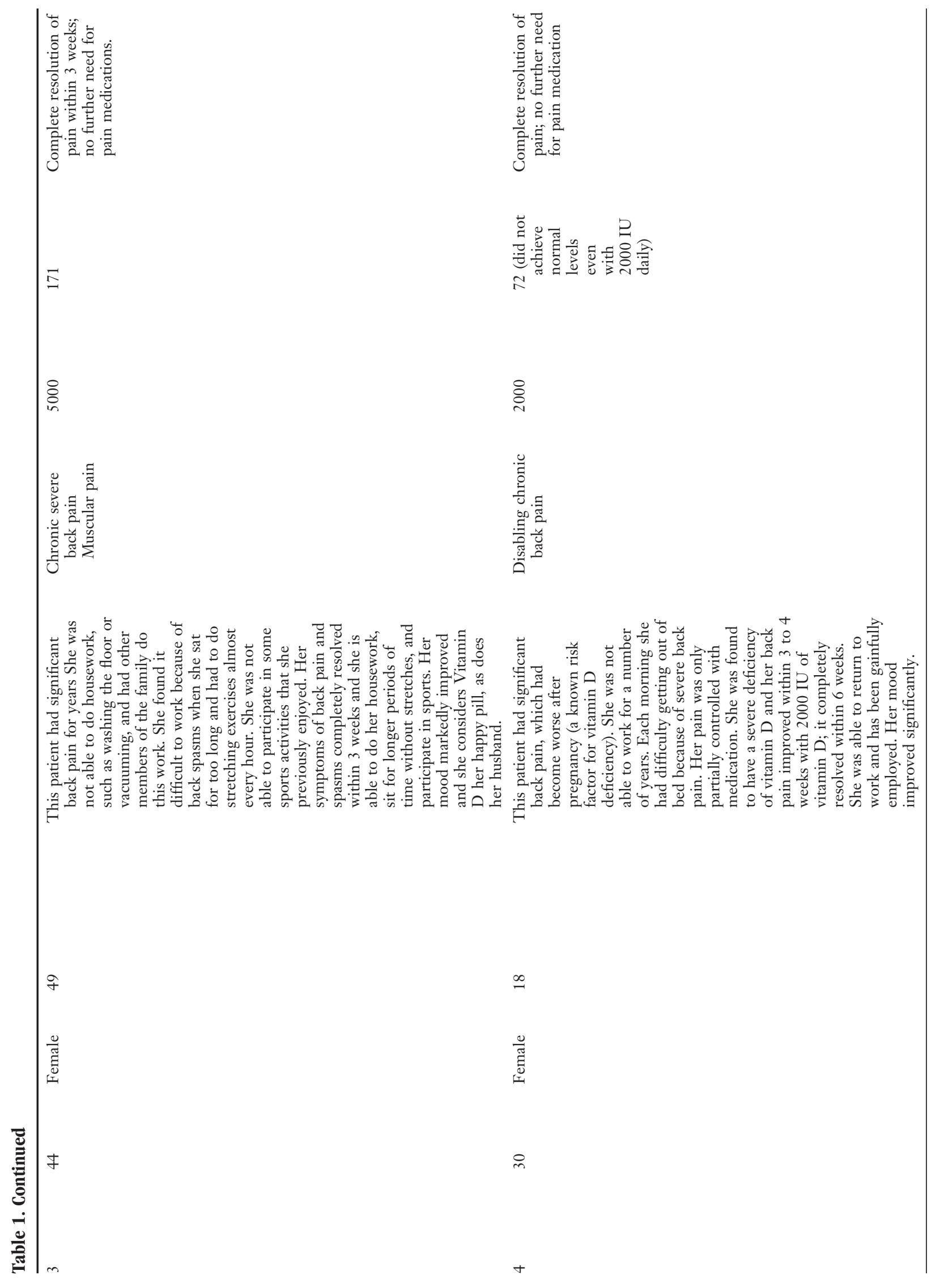




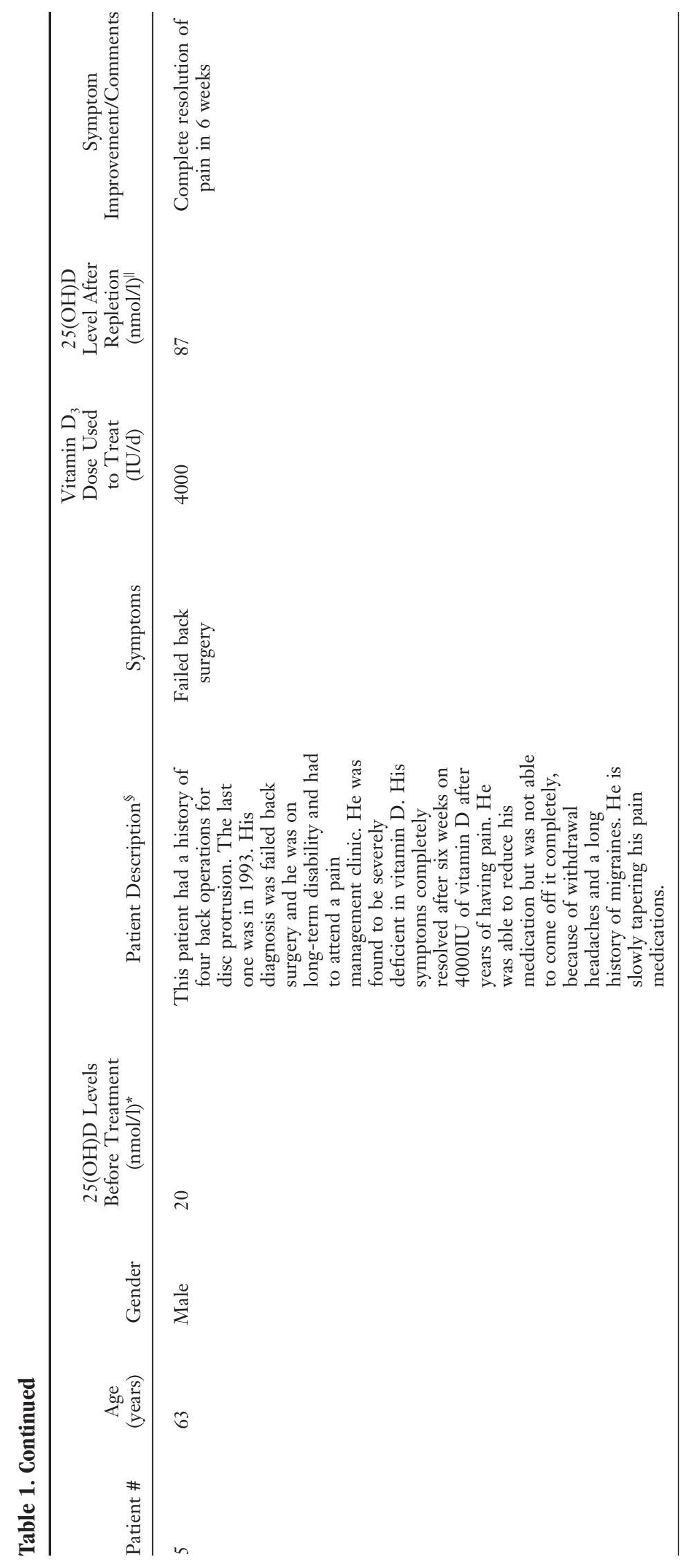




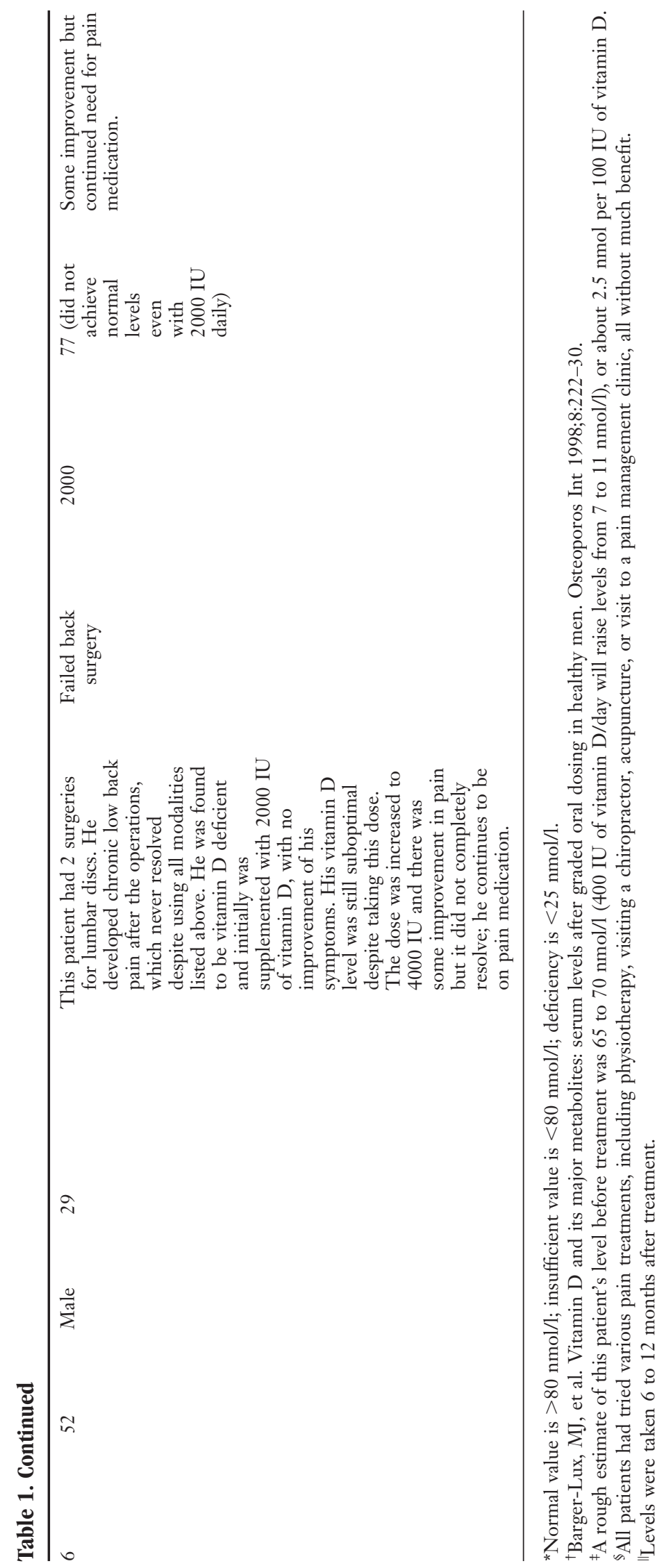


patients with vitamin D deficiency, ${ }^{5}$ as well as myopathy, which usually resolves more quickly than bone pain (which may take up to 1 year to resolve). ${ }^{2}$

Physicians should have a high index of suspicion for low vitamin D levels in patients with LBP, and determining the vitamin $\mathrm{D}$ status in these patients may be important. In those cases with vitamin D insufficiency/deficiency, repletion of vitamin D may offer dramatic results. Determining vitamin D levels and vitamin $\mathrm{D}$ repletion before and after back surgery may be prudent. The patients in this study who responded best used between 4000 and 5000 $\mathrm{IU}$ of vitamin $\mathrm{D}_{3} /$ day.

\section{Conclusion}

This case series supports information that has recently become apparent in the literature about vitamin D deficiency and its influence on back pain, muscle pain, and failed back surgery. Doses in the range of 4000 to $5000 \mathrm{IU}$ of vitamin $\mathrm{D}_{3}$ /day may be needed for an adequate response.

Placebo-controlled studies looking at outcomes in patients requiring back surgery with supplemen- tation of vitamin D are urgently needed. Likewise, randomized placebo-controlled studies assessing vitamin D status, vitamin D receptor genotyping, and outcomes (using standardized measures of the severity of LBP, function, and quality of life) on repletion of vitamin $\mathrm{D}$ in patients with chronic LBP are needed.

\section{References}

1. National Institute of Neurological Disorders and Stroke. Low back pain fact sheet. National Institutes of Health Publication number 03-5161. Washington DC: National Institute of Neurological Disorders and Stroke; 2003.

2. Francis RM, Selby PL. Osteomalacia. Baillieres Clin Endocrinol Metab 1997;11:145-63.

3. Al Faraj S, Al Mutairi K. Vitamin D deficiency and chronic low back pain in Saudi Arabia. Spine 2003; 28:177-9.

4. Plehwe WE, Carey RP. Spinal surgery and severe vitamin D deficiency. Med J Aust 2002;176:438-9.

5. Ghose R. Osteomalacia: recovery of bone density. N Z Med J 2004;117:U940.

6. Heath KM, Elovic EP. Vitamin D deficiency: implications in the rehabilitation setting. Am J Phys Med Rehabil 2006;85:916-23. 